\title{
PENDIDIKAN PROGRESIF DAN KAUM URBAN: MENCARI WAJAH BARU KONTRIBUSI SOSIAL
}

\author{
Elia Tambunan \\ elia.tambunan@gmail.com \\ STT Salatiga
}

\begin{abstract}
Abstraksi
Tulisan ini menunjukkan kontribusi sosial Pendidikan kaum urban dengan mengambil contoh Jungle School Salatiga. Dengan meneliti sejumlah literatur tentang pembelajaran transformatif bagi orang dewasa, data empiris terlihat bagaimana STT sebaiknya memperlihatkan aspek dan karakter sosial dalam proses dan lulusan. Kontribusi teoritis tulisan ini memperluas teori pembelajaran transformatif menjadi pendidikan progresif yang memiliki kebermanfaatan. Sedangkan praktisnya ialah praksis pendidikan urban yang dikelola lulusan hadir dalam paradoks Jawa Tengah, dilema modernisasi dan urbanisasi kota jajahan di Indonesia yang mengalami persaingan pendidikan dan segregasi kehidupan kota.
\end{abstract}

Kata Kunci: Pendidikan Urban Progresif, Paradoks Jawa Tengah, Kontribusi Sosial, Jungle School, Lulusan STT.

\begin{abstract}
Paper shows the social contribution of urban Education by examining the Salatiga Jungle School. By reading the literatures on transformative learning for adults, empirical data, it is examining how theological seminary performing the aspects and social character in learning process and outcomes. Paper contribution is enlarging the transformative theory into progressive education that has benefits. The practical contribution is presenting the praxis urban education in the paradox of Central Java, the dilemma of modernization and urbanization of the Indonesian colonies city which increases the education competition and segregation city life.
\end{abstract}

Keywords: Progressive Urban Education, Central Java Paradox, Social Contributions, Jungle School School, Theological Graduates.

\section{Pendahuluan}

Sekolah Tinggi Teologi (STT) dan orang-orang dalamnya hidup dalam arena sosial. Tetapi, kontribusi aktifnya terhadap arena sosial di mana mereka berada tidak terlalu dirasakan. Pembelajaran yang ada cenderung terkumpul sebagai pengetahuan belum dikondisikan untuk menciptakan sesuatu yang memiliki keserbagunaan. Secara personifikasi, inilah yang saya maksudkan seolah-olah Pendidikan Kristen kehilangan wajahnya sehingga perlu dicari kembali. Padahal, Jasin (1963), seorang staff Departemen Pendidikan dan Kebudayaan Republik Indonesia, tegas akui, Indonesia menjadi modern seperti sekarang tak lepas dari kontribusi pendidikan Kristen sejak era kolonialisme. Persoalannya, karena masih berkutat pada persoalan admisi dan akreditas kelembagaan, justru persoalan mutu isi, proses dan output kelembagaan STT sekarang terbengkalai 
(Aritonang, 2018: 97-106). Intelektualitas pendidikan tinggi Kristen di Indonesia sedang sakit akut. STT alami obesitas teologi tetapi kurus kering atau tidak bervitamin secara keilmuan. Itu akibat dari isi mata kuliah kurikulum teologi dan PAK bercorak indoktrinasi wajib ditempuh mahasiswa. Semangat akreditasi mutu dosen dan institusi berbanding terbalik dengan proses belajar mengajar dan lulusan. Jikapun banyak yang terakreditas perilaku "trik" dan "intrik" dalam proses memperolehnya tak terhindarkan (Tambunan, 2012: 96-138).

Tak seorangpun bisa membantah, bila STT sebagai lembaga pendidikan yang dikelola oleh Lembaga Kristen dibangun dengan tidak mungkin mengingkari misi sosial dalam panggilannya. Maka, dengan panggilan itu, STT tidak bisa menghindari tanggung jawabnya di dunia. Memang, setidaknya pada tahun 1939, Marique, dalam bukunya "The Philosophy of Christian Education," menjelaskan sejak awal abad ke-20 ada tren yang sedang terjadi dalam filsafat maupun praksis pendidikan Agama Kristen yakni semakin terbukanya tempat aspek dan karakter sosial di dalamnya. Para teoritis dan praktisi terus-menerus menyuarakan secara gencar agar orang-orang Kristen bergerak keluar ke ruang sosial lewat pendidikan (1939: 74).

Tuntutan terhadap perlunya akan aspek dan karakter sosial dalam pendidikan itu seakan menemukan momentum, ketika PBB lewat UNESCO sebagai badan yang mengurusi pendidikan dunia menetaskan kebijakan yang monumental, dalam konsep besar "Corporate Social Responsibility Partnerships." Penjelasannya sesuai dengan Sue Williams, semua korporasi besar di dunia dengan ladang bisnis besar dan keuntungan semakin membesar semakin diminta untuk memainkan perannya dalam upaya-upaya kolektif berjejaring untuk pembangunan berkelanjutan. Untuk tujuan ini, UNESCO secara bertahap membuka pintunya untuk sektor korporasi, mengundang perusahaan ke dalam kemitraan jangka panjang (2000: 4-5).

Tampak jelas, apa yang dimaksudkan aspek sosial selama ini ternyata memang masih dalam konsep besar pendidikan utamanya untuk masyarakat kota. Akan tetapi, dalam konsep besar itu pendidikan Tinggi Kristen semacam STT belum menjadi topik pembicaraan yang dianggap penting. Di sinilah kelebihan atau katakanlah kebaruan dari tulisan ini karena hendak memasukkan pendidikan di STT sebagai komunitas pendidikan Tinggi dengan pendekatan teori pembelajaran orang dewasa, atau adult learner biasa disebut, namun yang paling sering diabaikan, kata Chen (2017: 1-12), secara berkelanjutan sesuai dengan kebutuhan pribadi dan masyarakat di mana mahasiswa akan melayani. Satu lingkungan belajar bersifat komunitas lain dari pendidikan tradisional atau jenjang PAUD, TK, SD, SMP, dan SMA sebelumnya. Satu komunitas belajar terbuka akan tumbuhnya aspek, karakter, budaya, dan realita sosial dalam prosesnya. Sayangnya, justru hal seperti ini masih jarang dikaji di lingkup STT, bahkan proses pembelajaran di STT persis sama seperti pada jenjang di bawahnya. Bahkan, saya mengatakan sejak tahun 2012, mata kuliah mandiri di STT dengan nomenklatur sendiri penekanan kajiannya akan masalah-masalah sosial sama sekali tidak ada, kecuali hanya topiktopik pembahasan secara sporadis disinggung dalam berbagai mata kuliah (Tambunan, 2012: 63-72). 
Pertanyaannya, bagaimana dengan peran-peran sosial STT dalam menghasilkan lulusan untuk menjadi tokoh sentral di kehidupan sosial? Kontribusi apa dipersembahkan ke masyarakat? Bagaimana visi STT terhadap lulusan di tengah masyarakat jika kajian sosial minim? Fokus tulisan ini memperlihatkan elemen dasar dari aspek dan karakter sosial kelembagaan STT khususnya bagi mahasiswa S1, teristimewa S2 dan S3. Kemudian agar lebih mudah memberikan kajian terukur dan konkret, saya akan mengaitkannya dengan realita masyarakat kota dengan pertimbangan STT berlokasi di kota atau setidaknya di pinggiran kota.

\section{Metode Penelitian}

Secara metodologis, saya akan menggunakan kerangka pikir "Transformative Dimensions of Adult Learning" dari Jack Mezirow yang dipromosikan sejak tahun 1978 hingga 2013, untuk mengkaji dimensi sosial dari panggilan STT di arena sosial. Dengan meneliti sejumlah literatur terkait khususnya tentang Pembelajaran Orang Dewasa, dan menambahkan data lapangan dari Kota Salatiga di mana penulis tinggal ataupun dari beberapa pengalaman mengajar di sejumlah STT selama ini, maupun hasil-hasil riset terkait sebagai data penguat, akan terlihat bagaimana STT sebaiknya mampu memperlihatkan aspek dan karakter sosial dalam hal pelayananpelayanan sosial lewat aspek pendidikan agar orang-orang di STT sampai pada upaya menutup "gap" antara kampus dengan realita. Dari tulisan ini akan tampil relasi pendidikan tinggi Kristen di tengah kaum urban yang akan dimaksudkan menjadi sumbangsih akademik.

\section{Pendidikan Transformatif}

Dengan membaca Mezirow, pendidikan transformatif bermanfaat untuk mahasiswa sebagai pembelajar di STT untuk membentuk diri sendiri menjadi seorang atau kelompok entrepreneur Kristen setelah lulus, demikian halnya manfaat tersebut bagi STT sebagai lembaga dan dosen sebagai pendidik di dalamnya dalam berbagai sektor ministri dengan berbagai pendekatan pula namun yang selalu berciri edukatif. Secara teoritis, transformasi belajar oleh Mezirow diartikan bahwa belajar itu hendak mengkonstruksi makna, satu makna bukan untuk diketahui tetapi diubah menjadi alatalat berpikir dan bekerja. Artinya, makna itu dalam proses pendidikan ialah hasil bentukan oleh orang yang belajar, dengan belajar dari segala tempat menjadi satu kebiasaan (1991: 4). Sedangkan, dalam perkembangannya, para sarjana pendidikan orang dewasa mendefiniskan pembelajaran transformatif adalah teori pembelajaran orang dewasa yang memanfaatkan dilema membingungkan untuk menantang pemikiran orang yang belajar. Taylor dan Cranton melihat pembelajaran transformatif bukan memberikan tinjauan komprehensif dan kritis mengenai teori dalam pembelajaran materi di ruang belajar, tetapi memahami pembelajaran akan pengalaman dan realitas di lapangan yang terus mengalami transformasi dan dengan kedua hal itu, orang dewasa mengembangkannya kemudian yang sesuai dengan hidup pembelajar (2012). Belajar, seperti kata Cranton, harus diletakkan pada posisi untuk memahami dan mempromosikan pembelajaran yang mampu membawa orang dewasa memperoleh banyak wawasan baru dari pertumbuhan luar biasa yang terjadi di lapangan (2016). 
Jack Mezirow, kelahiran tahun 1923, meninggal tanggal 24 September 2014, adalah seorang sosiolog Amerika dan Profesor Emeritus untuk Pendidikan Dewasa dan Berkelanjutan di Teachers College, Universitas Columbia. Mezirow bergelar B.A., dan gelar M.A., dalam Ilmu Sosial dan Pendidikan dari University of Minnesota. Gelar Ed.D., dalam Pendidikan Orang Dewasa (POD) dari University of California, Los Angeles. Dia adalah pendiri Program Doktoral Adult Education Guided Intensive Study (AEGIS) di Teachers College, Universitas Columbia. Dalam karirnya, Mezirow dipengaruhi oleh Paulo Freire dan Jurgen Habermas. Secara luas, Mezirow diakui sebagai pendiri konsep pembelajaran transformatif. Namun, teori pembelajaran transformatif Mezirow telah diilhami oleh sejumlah pemikir penting semacam Thomas Khun, Paolo Freire, dan Jurgen Habermas. Merekalah peletak dasar berpikir bagi Mezirow untuk membangun fondasi dari teori pembelajaran transformatif yang kuat Illeris, 2009: 90105). Secara garis besar, seperti kata Calleja (2014: 117-136), ada tiga pengaruh awal dan paling penting pada pekerjaan Mezirow yang membantu untuk membentuk aspek dasar terkait dengan teorinya. Ini termasuk konsepsi filosofi Kuhn (1962) tentang paradigma, konsep Freire (1970) tentang "conscientisation", maksudnya kesadaran dalam domain pembelajaran, dan Habermas $(1971 ; 1984)$ tentang diskusi dialogis lewat bahasa sebagai tindakan komunikatif.

Dengan menggabungkan tiga tokoh dan konsep besar mereka, maka belajar menurut Mezirow, sebagai proses menggunakan interpretasi atas pengalaman sebelumnya untuk mendapatkan interpretasi baru atau revisi dari makna pengalaman dan perspektif sendiri untuk memandu tindakan masa depan. Dalam hal ini, seolah-olah orang dewasa diwajibkan telah mampu memproyeksikan gambar dan simbolik model, skema makna berdasarkan pembelajaran sebelumnya ke pengalamannya secara sensorik dan secara imajinatif. Materi apa yang dipelajari di dalam kelas belajar selalu dimaknai secara analogis untuk menafsirkan pengalaman baru (1996: 237-239).

Aslinya, kerangka teori ini dikembangkan oleh Mezirow sejak tahun 1978 ketika mengamati orang-orang dewasa, khususnya para wanita yang putus sekolah di California, Amerika Serikat. Penelitian asli Mezirow fokus pada perubahan perspektif yang dialami oleh ibu-ibu yang kemudian "kembali ke pendidikan formal" setelah lama istirahat dari sekolah. Penelitiannya menyingkapkan wawasan luas tentang bagaimana memahami belajar di masa dewasa dan peran pembelajaran sebelumnya (1978). Yang sangat ditekankan oleh Mezirow dalam konsep itu ialah perspektif transformatif komunitas secara luas, bukan hanya di lingkup internal siswa di dalam kelas dan lembaganya (1978: 100-110). Belajar bukan untuk pengetahuan teoritis dalam kelas untuk pemahaman pribadi semata, tetapi justru untuk pengalaman di kehidupan luas (1981: 3-24; 1985: 25).

Penelitian awal dan penelitian lebih lanjut dari Mezirow membawanya untuk menyimpulkan bahwa orang dewasa tidak hanya membuat aplikasi cara lama belajar untuk situasi baru, sebaliknya mereka menemukan kebutuhan untuk mendapatkan perspektif baru dalam rangka mendapatkan pemahaman yang lebih lengkap tentang perubahan peristiwa di sekitarnya. Mezirow kemudian menciptakan proses "aksi reflektif sebagai dimensi perubahan dalam belajar orang dewasa sebagai satu kerangka 
kerja sebagai perspektif pendidikan transformasi. Mezirow terus menemukan konsistensi dalam pelajar dewasa yang dipelajari oleh mereka dengan beberapa tahapan (1990).

Tabel 1: Fase Pembelajaran Transformatif Mezirow

\begin{tabular}{|c|c|}
\hline Tahapan & Identifikasi Fase sebagai Proses Pembelajaran \\
\hline Fase 1 & Dilema yang membingungkan \\
\hline Fase 2 & Pemeriksaan diri dengan perasaan bersalah atau malu atas keadaan \\
\hline Fase 3 & Penilaian kritis asumsi epistemik, sosiokultural, atau psikis \\
\hline Fase 4 & $\begin{array}{l}\text { Pengakuan bahwa ketidakpuasan seseorang dan proses transformasi dibagikan } \\
\text { dan bahwa orang lain telah menegosiasikan perubahan }\end{array}$ \\
\hline Fase 5 & Eksplorasi opsi untuk peran, hubungan, dan tindakan baru \\
\hline Fase 6 & Perencanaan suatu tindakan \\
\hline Fase 7 & $\begin{array}{l}\text { Akuisisi pengetahuan dan keterampilan untuk mengimplementasikan rencana } \\
\text { seseorang }\end{array}$ \\
\hline Fase 8 & Sementara mencoba peran baru \\
\hline Fase 9 & Membangun kompetensi dan kepercayaan diri dalam peran dan hubungan baru \\
\hline Fase 10 & $\begin{array}{l}\text { Reintegrasi ke dalam kehidupan seseorang berdasarkan kondisi yang ditentukan } \\
\text { oleh perspektif seseorang }\end{array}$ \\
\hline
\end{tabular}

Dari kerangka pikir dengan 10 tahapan Mezirow tersebut, tampak jelas sekali bahwa belajar di masa dewasa ialah membina refleksi kritis di tengah masyarakat luas. Mereka didorong untuk menggunakan pemikiran kritis dan bertanya untuk mempertimbangkan apakah asumsi dan keyakinan mendasar apa yang mereka pelajari tentang dunia nyata itu akurat dan berguna untuk hidupnya dan orang banyak (2009: 168-169).

Dengan menggunakan kontribusi luas Jack Mezirow pada pemahaman tentang pengalaman pembelajaran transformatif orang dewasa akan membantu dalam memahami pergeseran terstruktur dialami oleh individu yang memungkinkan diri mereka untuk belajar dari pengalaman mereka sendiri dalam suatu komunitas masyarakat sehingga nanti STT mampu meluluskan mahasiswa yang sesuai dengan kebutuhan setempat. Mengapa, karena sesungguhnya, seperti dijelaskan oleh Mezirow, justru kembali kepada proses pembelajaran yang tidak terlalu mempusingkan diri akan soal-soal apa yang dipelajari tetapi justru apakah pembelajaran itu berasal dari atau sesuai dengan keadan masyarakat sosial seperti apa yang akan dimasuki oleh para mahasiswa. 
Pembentukan karakter mahasiswa sebagai "murid Kristus" yang ada di sekolah, seperti banyak disuarakan oleh Lickona (1976: 400; 1992: 7; 2004: 277), tetapi saya melihat dalam lansekap yang lebih dan bermanfaat ke luar untuk kebutuhan perubahan masyarakat dengan karakteristik dan nilai kekeristenan yang berdampak nyata.

Sekaitan dengan kerangka pikir pendidikan transformatif, mahasiswa STT secara umur maupun maknawi diposisikan sebagai pembelajar dewasa. Lalu, Mahasiswa STT bila dikaitkan dengan konsep andragogi (maksudnya cara belajar untuk pendidikan orang dewasa), seperti dipopulerkan oleh Knowles di Amerika sejak tahun 1998, maka cara memahami pembelajaran orang dewasa berakibat pada bagaimana melakukan pedagogi pembelajaran untuk orang dewasa tersebut (1998). Mahasiswa di STT memang tepat sekali ditempatkan pada posisi orang yang kemudian "kembali ke pendidikan formal" setelah lama istirahat dari sekolah di jenjang bawah sebelumnya. Ini menjadi bukti, bahwa di tengah masih banyaknya sejumlah negara dunia ketiga mengakses dan menerapkan konsep pendidikan untuk semua orang (Education for All) yang digagas UNESCO sejak tahun 1990 dalam The World Conference on Education for All di Jomtien, Thailand (Vink, 2020), STT adalah satu lembaga yang telah sejak awal selalu menerima mahasiwa yang sudah berkeluarga dan berusia lanjut sekalipun diterima sebagai murid. Bahkan, STT juga telah menerapkan pendidikan seumur hidup (Life-Long Education) yang digagas UNESCO di Place de Fontenoy, 75700 Paris, France sejak tahun 1971 (Parkyn, 1973: 7). Maksudnya, seperti dijelaskan oleh PD Shukla, menerima mahasiswa sebagai orang dewasa pembelajar yang tidak dibatasi oleh umur (Shukla, 2018). Artinya, UNESCO sudah sejak awal mengupayakan pendidikan tidak lagi mengalami pembatasan ruang, waktu, usia dan tempat. Carlsen, Holmberg, Neghina, Owusu-Boampong, 2016: 16). Seperti kata Lengrand, satu model dan kesempatan berpendidikan yang wajib dilaksanakan di seluruh dunia sejak konsep itu diluncurkan UNESCO (1970: 73).

Dengan mengingat penjelasan paragraf di atas, maka dalam batas-batasan tertentu pembelajaran transformatif jelas sekali dapat diterapkan di STT. Dengan demikian, semestinya mahasiswa STT sangat tepat untuk bisa dianggap telah mengalami kehidupan sosial yang terkait dengan persoalan kultural dengan konteks yang ada. Pengalaman tersebut semestinya mampu membentuk pikiran dan perspektif kritis, memotivasi dan membentuk mereka untuk mendapatkan apa-apa saja yang mereka butuhkan dalam hidup sosial mereka selanjutnya. Cara orang dewasa belajar, seperti kata Merriam, Bierema, tidak lagi seperti cara-cara tradisional layaknya cara belajar anak dan remaja tetapi belajar didorong oleh kebutuhan hidup sendiri dan pengalaman hidup sendiri yang membentuk tubuh dan semangat pengetahuan mereka (2013). Dengan bertambahnya usia sebagai orang dewasa, maka mahasiswa paham apa yang mereka butuhkan dalam kehidupannya yang selalu terkait dengan hal-hal kultural dan konteksnya tersebut. Karena secara teoritik, Drago-Severson, mengatakan, pembelajar yang tumbuh paling baik di sekolah di mana seseorang telah dewasa dan kedewasaan di sekitar mereka juga tumbuh dengan baik (2009).

\section{Pembelajaran Transformatif ke Pendidikan Progresif}


Dengan tuntas membaca Mezirow, pendidikan transformatif kini menjadi serangkaian kerangka berpikir dan bekerja, namun dengan menambahkan beberapa pemikiran tokoh lain, yang terbilang lengkap bagi mahasiswa, STT, dan dosen untuk memiliki kelengkapan kerja berparadigma progresif untuk mengupayakan berbagai sektor ministri dengan berbagai pendekatan berciri edukatif yang memiliki serba kemanfaatan. Dari sub poin di atas telah dijelaskan pendidikan transformatif dimaknai sebagai satu hal pembelajaran bagi dan oleh orang dewasa secara usia yang bersifat berubahubah bentuk, rupa, macam, sifat, keadaan, dan sebagainya dalam seluruh lembaga baik isi maupun prosesnya.

Hal yang perlu dikritisi dari Mezirow adalah siapa subjek belajar. Dalam teorinya, para pembelajar dianggap telah dewasa dan memiliki pengalaman dan kemampuan berpikir layaknya orang dewasa. Mezirow dalam mengembangkan teori pendidikan transformastif tersebut, seperti kata Taylor, sangat mementingkan sentralitas pengalaman sebagai kerangka rujukan seseorang yang menimbulkan refleksi kritis dan refleksi diri yang kritis terhadap wacana kompleks yang ada di sekitar pembelajar (1997: 34-59). Mezirow juga menekankan dimensi sosial dalam pembelajaran transformatif dengan menunjukkan pentingnya berinteraksi dengan orang lain untuk mengidentifikasi perspektif alternatif dalam memberikan dukungan emosional selama proses transformasi, untuk menganalisis interpretasi sendiri atas situasi seseorang dari berbagai sudut pandang, untuk mengidentifikasi dilema seseorang sebagai pengalaman yang dibagikan dan dinegosiasikan (2000).
Mezirow, karena subjek penelitiannya sejak tahun 1987 adalah ibuibu yang putus sekolah karena alasan urusan domestik atau sejumlah wanita yang sempat terhenti sekolah akibat berbagai halangan dengan terbukanya kesempatan dan adanya dukungan finansial, mereka kembali bersekolah dalam keadaan sudah menjadi orang dewasa. Dengan subjek riset dalam keadaan persoalan seperti itu, maka tidaklah mengherankan apabila ia mengandaikan semua orang belajar layaknya orang dewasa berpikir (2012: 7395).

Dalam penjelasan ini saya akan mengembangkannya lebih lanjut dengan apa yang disebut sebagai pendidikan progresif. Saya memaknai progresif sebagai proses pembelajaran orang dewasa yang berhaluan ke arah pendidikan yang memberikan ruang dan kesempatan bagi mahasiswa selama proses pembelajaran yang dimaksudkan rangka menciptakan sesuatu dengan penuh kebebasan. Satu kemampuan yang disediakan kampus dan dosen bagi kebutuhan hidup nyata mahasiswa untuk memperbaikan keadaan sekarang ke arah kemajuan di dalam komunitas masyarakat khusus. Dalam pengertian lain, belajar bukan lagi untuk mempunyai informasi atau pengetahuan yang dikumpulkan dan dibangun dari pengalaman secara reflektif dan kritis seperti inti teori transformastif dari Mezirow. Tetapi, mahasiswa STT belajar dan berpendidikan yang memiliki keserbagunaan untuk membuat sesuatu. Dalam arti luasnya secara teologis, satu pendidikan Kristen yang bukan lagi hanya menekankan keselamatan teologis secara eksklusif yang justru kadang mengasingkan panggilan sosial untuk melakukan perubahan di masyarakat misalnya dengan satu hal yang konkret. Pada bagian lain hal 
itu akan saya tunjukkan Jungle School sebagai satu contoh.

Dengan pendidikan progresif, mahasiswa STT saat bersamaan tetap menebarkan berita "keselamatan sosial" seimbang dengan kesejahteraan sosial, juga memperlihatkan diri mereka ke publik sebagai orang atau kelompok masyarakat yang telah menerima keselamatan. Caranya dilakukan dengan memerhatikan dan memenuhi kebutuhan hidup masyarakat lewat sektor pendidikan. Apalagi, landasan biblika yang ada sangat jelas untuk mendasari hal itu. Orang Kristen diajarkan oleh Firman Allah untuk menjadi tetangga yang baik dengan diukur dari posisi dan keadaan aktif, yakni berkontribusi secara sosial termasuk untuk masyarakat kota. Terbukti seperti tertulis dalam Amsal 27 ayat 10: "Jangan kau tinggalkan temanmu dan teman ayahmu. Jangan datang di rumah saudaramu pada waktu engkau malang. Lebih baik tetangga yang dekat dari pada saudara yang jauh." Dan Yeremia 29 ayat 7: "Usahakanlah kesejahteraan kota ke mana kamu Aku buang, dan berdoalah untuk kota itu kepada TUHAN, sebab kesejahteraannya adalah kesejahteraanmu." Saya menerjemahkan dua ayat ini relatif secara lebih longgar. Orang Kristen diwajibkan membangun iman teologi dan sosial berjalan bersamaan berada di antara orang banyak saat bersamaan berarti memperhatikan dan memenuhi kebutuhan orang-orang tersebut. Sama halnya dengan kerja teologis seperti diajarkan agama Kristen harus bersamaan pula dengan kerjakerja sosial untuk kesejahteraan masyarakat.

Berbeda dengan Mezirow yang menekankan subjek belajar, saya justru menambahkan hal yang lebih utuh dalam lingkup internal civitas akademik dan dimensi sosial dari realitas masyarakat, antara lain masyarakat kota yang wajib masuk secara integratif dalam kajian-kajian di kampus bahkan semestinya memiliki mata kuliah dengan nomenklatur mandiri. Artinya, pembelajaran progresif bukan lagi mengejar ketuntasan menyelesaikan mata kuliah dengan seluruh pokok-pokok bahasan 2 SKS misalnya yang sangat melelahkan, membosankan, bahkan memberatkan selama 14 hingga 16 tatap muka, tetapi dengan selektif, STT, Dosen dan mahasiswa harus bisa memastikan, mana-mana saja pokok bahasan tersebut memang ada gunanya untuk kehidupan mahasiswa dan masyarakat. Seperti kata Cranton dan Taylor menjelaskan belajar yang dibuat oleh Mezirow menjadi berbeda dengan ahli lainnya karena bertujuan membantu individu menjadi sadar akan struktur yang menindas dan mengubahnya untuk tujuan politik yang memaksa perubahan ekonomi di masyarakat (2012). Itu bisa dilakukan demikian, karena seperti kata Cranton, sebenarnya Mezirow, dalam teori belajar transformatifnya, harus ada kebebasan untuk menekankan kehendak bebas dari pelajar dalam mengintegrasikan kembali perspektif baru ke dalam kehidupan dan bertindak dalam dimensi sosial (2013: 267-274).

Untuk itu terlibat dalam pendidikan progresif, STT sebagai lembaga, Dosen sebagai saya sebut sebagai "partner atau supporter kata Mezirow" belajar bagi mahasiswa, dan mahasiswa itu sendiri sebagai sebagai pembelajar, wajib tahu tentang dan memiliki pendidikan untuk keserbagunaan daripada hanya terlatih untuk kemampuan belajar, seperti kata Husen (1968: 190-209). Maka dengan teori keserbagunaan itu, kampus dan dosen serta mahasiswa itu sendiri harus bisa memastikan apakah muatan pelajaran itu berguna untuk masyarakat di mana 
mahasiswa itu akan tinggal selanjutnya. Torsten Husen juga berkata, pembelajaran yang modern adalah yang kooperatif dan egaliter yang menonjolkan hubungan berpengetahuan dan berketerampilan (1968: 87-99).

Maka dengan teori keserbagunaan itu, mahasiswa di STT bukan hanya terampil belajar dan berpengetahuan teologis atau pun pendidikan agama Kristen bagi yang memilih program studi PAK, tetapi memiliki keterampilan spesifik yang dipakainya untuk kebutuhan masyarakat yang luas. Contohnya, mahasiswa PAK tidak hanya terampil mengajar mata pelajaran PAK di sekolah tetapi harus terampil mendirikan lembaga pendidikan miliknya sendiri, baik itu secara indivual maupun bersifat "joint venture" dengan badan lain yang menaruh hati kepada sektor pendidikan. Dengan keserbagunaan itu harus bisa dipastikan selama dalam proses berpendidikan, mahasiswa di STT memiliki apa yang disebut Jerome Bruner sebagai sensibilitas belajar kompleks yang dapat dipahami sesuai dengan pengalaman orang bersangkutan (1960: 43). Contoh, mahasiswa PAK selama ini dilihat dari isi kurikulum PAK sebanyak 50\% misalnya dan proses belajar yang menekankan ilmu mengajar sebagai guru dengan kewajiban untuk mengetahui hal-hal teknis administratif, maka terang sekali realitas yang ada di dalamnya tidak bisa disangkal. Mahasiswa memang hanya diproyeksikan sebagai kuli kerja dengan strata rendah atau kelas menengah saja, di mana yang dengan lebih halus disebut sebagai guru.

Sama halnya dengan mahasiswa Teologi dengan muatan kurikulum teologi yang banyak dan padat mereka sangat hebat dalam mengkaji persoalan-persoalan spiritualitas di masyarakat dengan kaca mata teologis. Sayangnya, mereka lemah dalam hal memfungsionalkan kekuatan secara kolektif untuk perubahan sosial. Tentu saja kelemahan itu tidak di pihak mahasiswa. Akan tetapi jelas sekali lemahnya mahasiswa itu harus dilihat sebagai representasi dari tidak pahamnya STT sebagai lembaga dan para pengelolannya menjadikan pendidikan tinggi Kristen sebagai instrumen perubahan dan pembangunan sosial di Indonesia. Sebagai contoh, saya ambilkan dari kasus makin terjadinya dekadensi moralitas Amerika. Oleh Hammod, dianggapnya karena pendidikan tinggi Kristen, khususnya di kalangan Evangelikal sudah lama tidak lagi menjalankan fungsi sebagai suara reformasi sosial. Padahal, dalam sejarahnya tahun 1940-1950 kelompokkelompok Evangelikal maupun Reformed dikenal sebagai kelompok Kristen yang membawa isu-isu moralitas dan sosial etis menjadi isu politik dan menyuarakannya dengan keras. Gerakan pendidikan Kristen awalnya difokuskan tidak hanya pada upaya pelayanan penginjilan, tetapi juga pada pendidikan sebagai sarana utama untuk membentuk budaya bangsa Amerika. Akan tetapi, beberapa dekade terakhir hal itu bukan lagi menjadi tradisi utama kelompok ini. "Suara sosial kenabian" mereka redup (2019: 3-15).

Seharusnya, dengan memasukkan dimensi sosial yang diintegrasikan ke dalam budaya belajar di lingkup civitas akademik, STT sebagai lembaga pendidikan, dosen sebagai "partner atau supporter belajar, dan mahasiswa sebagai subjek belajar sudah wajib dikondisikan dan disosialisasikan sebagai "entrepreneur" pendidikan. Walaupun nanti, karena sifat panggilan guru atau pendidik amat kuat dalam DNA, mereka akan tetap bisa menjadi tenaga pendidik di dalamnya, namun dalam posisi sebagai pemilik atau 
pendiri bukan lagi sebagai kuli kerja untuk orang lain, yang mana mungkin saja pendiri yayasan atau pemilik lembaga tersebut sama sekali justru tidak berorientasi edukasi sedikitpun tetapi hanya mengumpulkan kapital ekonomi dengan cara merekayasa pendidikan sebagai bisnis.

Mahasiswa Teologi dengan muatan kurikulum teologi yang banyak dan padat mereka semestinya bukan lagi hanya menjadi ahli dalam kajian persoalan spiritualitas di masyarakat dengan kaca mata teologis. Tetapi, mereka juga seharusnya menjadi manusia hebat dalam hal pemasaran isi teologi yang menjadi keahliannya dalam sejumlah kemasan dan produk-produk yang layak jual dalam berbagai paket yang disenangi oleh kaum kota berduit misalnya. Aneh rasanya melihat fenomena sekarang. Pendeta lulusan STT konsumen seminar berbayar yang diselenggarakan motivator berlatar belakang ekonomi dan psikologi cerdik mengkomersialisasi teologi dalam paketpaket berbagai judul dengan harga belasan bahkan puluhan juta rupiah sekali pertemuan. Itu sudah saya suarakan sejak tahun 2012.

Kelemahan mendasar bagi mahasiswa Teologi selama ini ialah karena teologi dipandang sebagai pengetahuan kumulatif akan Allah dengan segala pokokpokok bahasan di dalamnya mulai semester 1 di S1 hingga semester 12 jenjang S3. Teologi tidak pernah dianggap menjadi sesuatu yang fungsional sebagai sains yang mampu menghidupi (Tambunan, 2012: 311). Persoalan itu muncul dari sikap fanatisme STT sebagai lembaga, dosen dan mahasiswa, termasuk masyarakat Kristen sebagai pengguna lulusan, yang mengambil titik awal intelektualnya dari wahyu ilahi yang terkandung dalam Alkitab sebagai rangkuman teologi. Dalam pandang picik seperti itu, maka benarlah penjelasan Ellison dan Douglas (2010: 254), Hermans, dan Moore, teolog senang mengagungkan ilmu hermeneutik teks, lalu dibumbui dengan asumsi dan paradigma pewahyuan (2004: 49), tetapi gagap dalam hermeneutik kehidupan.

Semestinya, teologi sebagai sains ibarat sebagai alat pemrograman berpikir, logika deskripsi di dalam intelijensi, penalaran komprehensif dan investigatif, agen untuk merekonstruksi teori untuk bisa dipakai, penalaran otomatis yang berguna untuk kehidupan luas, dan juga bisa berfungsi sebagai mesin belajar tentang segala hal dalam kehidupan bukan hanya urusan agama belaka. Mahasiswa STT semestinya diajar memposisikan teologi dan PAK untuk tujuan menemukan kebenaran nyata dalam kehidupan di balik pernyataan-pernyataan Alkitab yang tampak setiap hari secara investigatif. Karena, segala sesuatu dalam kelas-kelas pembelajaran harus dikaji dalam wilayah ilmu pengetahuan atau pemahaman akademik yang terbuktikan oleh data, fakta, dan prosedural ilmiah. Kehidupan nyata jangan dipaksa masuk ke dalam keranjang teologi oleh anggapan teologis mahasiswa. Di sini, yang ingin ditegaskan seperti kata Newton, panggilan dari teolog ialah juga seorang ilmuwan untuk memberikan penjelasan disertai alasan rasional, dan pembuktian secara empiris jika tidak lebih baik mengakui memang tidak tahu sama sekali (1934). Meskipun pengetahuan manusia bersifat terbatas dan memiliki kekurang lengkapan atau bersifat temporer dan selalu hipotetikal, tetapi ia harus dipekerjakan untuk memahami dan menemukan sendiri makna dan isi kebenaran di dalam teologi agar memiliki keterkaitan erat dengan kenyataan di lapangan (Moser, Nat, 1987: 66). Dengan 
pendidikan progresif, arah kebijakan pendidikan STT bukan meluluskan para "staf ahli" yang tangkas dalam mengamati persoalan sosial tetapi kebijakan yang menetaskan para lulusan sebagai pengelola komunitas yang cakap agar mereka termobilisasi ke dalam perubahan sosial. Karena untuk itulah mereka kuliah di berbagai jenjang S1, S2, S3 STT selama ini.

Untuk mendapat lulusan STT yang transformatif, menurut Mezirow peran tenaga pendidik menjadi sentral. Dalam artian, dosen bukan sebagai pemegang keputusan apa yang pantas atau tidak yang wajib dipelajari oleh mahasiswa tetapi berposisi sebagai "partner atau supporter" belajar. Sentralitasnya sebagai pendidik sesuai dengan nilai-nilai yang diyakini bisa dipastikan mendukung mahasiswa dalam pencarian tujuan hidup, membantu mereka dalam penelitian, merencanakan taktik, dan mengembangkan keterampilan yang diperlukan untuk tindakan yang tepat dalam mengatasi kendala kehidupan sosial. Belajar Mezirow dipengaruhi konsepsi filosofi Kuhn tentang paradigma, dimana paradigma belajar muncul dari realita di luar kehidupan mahasiswa. Konsep Freire juga ada di sana, bahwa mahasiswa harus mengasah dan memiliki "conscientisation", maksudnya kesadaran akan adanya dunia luar sebagai domain penting dalam bahan pembelajaran. Selanjutnya, teori belajar tersebut tampak dari pengaruh Habermas yang menghendaki pembelajarn berlangsung bukan hanya dialog di dalam kelas antar sesama mahasiswa, dan dengan dosen, tetapi secara dialogis dan tindakan komunikatif bersama masyarakat. Dalam ini, Mezirow melihat peran dosen wajib memberi ruang bagi kehendak bebas mahasiswa dalam mengintegrasikan kembali pengalaman hidup untuk membangun perspektif baru ke dalam kehidupan dan bertindak dalam dimensi sosial (1989: 169-175).

Dengan demikian, dalam kebutuhan hidup yang lebih luas dan semakin kompleks, saya menjadi kurang seide dengan Dockery, bahwa nilai-nilai inti pengajaran Kristen hadir dalam upaya penanaman doktrin kebenaran dan membangun iman sebagai fondasi hidup kekristenan di masa mendatang (2019: 296308). Justru lebih tepat apa yang dijelaskan Wildemeersch, Finger, dan Janses, pendidikan adalah pertanggung jawaban sosial Kristen kepada Tuhan, manusia, masyarakat dan diri Kristen itu sendiri yang dapat mendamaikan setiap orang karena kebutuhan mereka terpenuhi (2001: ix). Yang dibutuhkan adalah lingkungan pembelajaran yang bisa mempererat hubungan mahasiswa dengan Kristus tanpa terasing, merasa tertolak kehidupan sosial dan kelompok pergaulannya. Dengan mengatakan ini, seperti kata Shires dan Miller, pendidikan memiliki tanggung jawab untuk membawa kekristenan dapat hidup alami dan bertumbuh dengan segar dalam skema masyarakat modern (1943: 196-201). Saya setuju dengan Kim, Kellough, kompetensi pendidikan Kristen yang ada tak lebih dari penggabungan seni, estika, etika spiritual, sosial dan intelektual yang mengejar ilmu untuk menterampilkan mahasiswa belajar dan mengajar (1983: vii).

Dengan dilihat dari kaca mata mahasiswa STT sebagai pembelajar orang dewasa dalam kebutuhan hidupnya yang lebih kompleks, belajar bukan lagi untuk membentuk kehidupannya seperti dalam pendidikan tradisional dan klasik di jenjang sebelumnya tetapi untuk membentuk apa yang saya sebut saja sebagai konstruksi pengetahuan yang terdiri dari tipe 
pembelajaran, tubuh pengetahuan, aspek dan karakter sosial, dan metode belajar.

Tabel 2: Konstruksi Pengetahuan

\begin{tabular}{|c|c|c|c|}
\hline $\begin{array}{l}\text { Tipe } \\
\text { Pembelajaran }\end{array}$ & Tubuh Pengetahuan & $\begin{array}{l}\text { Aspek dan Karakter } \\
\text { Sosial }\end{array}$ & Metode Belajar \\
\hline Teknis & $\begin{array}{l}\text { Alat kelengkapan } \\
\text { untuk memiliki }\end{array}$ & Bisa dikerjakan & Empiris-analitis \\
\hline Praktis & $\begin{array}{l}\text { Pemahaman untuk } \\
\text { mengetahui }\end{array}$ & Mampu berinteraksi & Hermeneutik-tafsir \\
\hline Emansipatoris & $\begin{array}{l}\text { Refleksi untuk } \\
\text { membentuk }\end{array}$ & $\begin{array}{l}\text { Memiliki kekuatan } \\
\text { atau pengaruh }\end{array}$ & Teori Kritis \\
\hline Transformatif & Pengalaman kritis & Berdampak & Inquiris-Discoveris \\
\hline Progresif & $\begin{array}{l}\text { Kontribusi terukur dan } \\
\text { dirasakan }\end{array}$ & $\begin{array}{l}\text { Menciptakan manfaat } \\
\text { nyata }\end{array}$ & $\begin{array}{l}\text { Berbasis } \\
\text { Grounded-Realistis } \\
\text { namun futuris }\end{array}$ \\
\hline
\end{tabular}

Terlihat di tabel atas ada benarnya yang dikatakan Marsick dan Mezirow, bahwa pembelajaran tak lagi untuk membentuk orang yang hidup dalam keadaan berbedabeda. Malah, pembelajar dengan cara yang mereka dapat kenali melalui refleksi kritis, terlibat dalam wacana, dan secara reflektif dan kritis mengambil tindakan untuk membentuk keadaan berdasarkan realitas keadan tersebut juga (2012). Pendidikan memang harus diposisikan sebagai instrumen untuk melakukan reformasi pengajaran secara global (Segall, 2006: 181). Dengan mempertimbangkan penjelasan ketiga ahli tersebut, belajar bagi Mahasiswa STT tak lagi hanya soal menemukan dan melanjutkan ke cara baru untuk memahami, berpikir, memutuskan, merasakan, tetapi belajar untuk menemukan cara baru untuk bertindak dalam membuat perubahan sosial berdasarkan pengalaman hidup mereka.
Tak salah bagi mahasiswa STT merefleksikan dalam hidupnya apa yang dikatakan Finger dan Asun. Belajar adalah jalan keluar dari peradaban manusia. Kekristenan seharusnya juga telah menjadi masyarakat belajar yang bersedia untuk belajar dengan sungguh dan dilakukan oleh individu yang menginspirasi dan memengaruhi individu, dan masyarakat yang menggemari hal edukatif (2001: 1-2).

Meskipun ada benarnya dalam beberapa hal, tetapi saya tidak bersetuju total kata Boggs, Associate Professor of Adult Education dari Ohio State University. Menurutnya, sisi pandang keagamaan Kristen sebagai elemen yang paling esensial dari ide kedewasaan Kristen adalah kapasitas dan kemampuan untuk bertumbuh. Kekristenan tidak hadir untuk menghindari dari tantangan dan masalah tetapi untuk menjelajahinya, hidup di dalamnya dan menyelesaikannya bahkan 
meskipun dengan konsekuensi kesalahan yang timbul akibatnya demi mencapai atau mengejar ide pertumbuhan sebagai orang Kristen (1989: 1-10). Dari Boggs itu, justru saya ingin berpikir lebih progresif. Seorang Kristen belajar atau hidup bukan cuma hanya bertumbuh tetapi melakukan sesuatu dengan pertumbuhan yang dicapai dan dikejar itu. Apalah gunanya iman, ilmu, atau kekayaan seorang Kristen bertumpuk dan bertumbuh jika ia tidak menciptakan sesuatu untuk orang lain dengan semua capaian petumbuhan itu? Oleh karena itu, berikut ini, saya akan menjadikan Jungle School (selanjutnya disingkat JS) sebagai satu contoh untuk memperlihatkan kontribusi masyarakat Kristen terhadap modernisasi dan urbanisasi kota-kota jajahan di Indonesia di bidang pendidikan masyarakat kota yang mengalami segregasi kehidupan kota dan persaingan pendidikan (Tambunan, 2018: 107-121).

\section{Pendidikan Milik Kristen dalam Paradoks Kota Jawa Tengah}

Menurut Ricklefs, periode tahun 1600-an hingga 1900-an, orang Jawa menjadi salah satu kelompok etnis terbesar di dunia Muslim yang sukses mengalami islamisasi di dalam politik lokal, sosial, budaya dan agama melalui pendidikan agama Islam, baik tradisional maupun modern (2008: 202; 2012: 21-22, 98). Menurut Subhan, ilmu-ilmu Islam yang berkembang dari generasi ke generasi. Lembaga pendidikan Islam juga telah mengalami transformasi dan modernisasi. Dia muncul sebagai lembaga pendidikan modern dengan penekanan tidak hanya pada sains Islam tetapi juga pada sains modern (2012: 3). Bahkan, Zahnd melihat bahwa gerakan sosial-spasial, budaya, agama, Islam dengan cepat terintegrasi dalam budaya Jawa dan menjadi komponen penting dari lingkungan budaya Jawa. Dalam perkembangan Islam, tak terpungkiri Islam berhasil menduduki ruang fisik di Jawa Tengah. Islam bahkan berhasil berintegrasi dengan lingkungan dan budaya setempat (2008: 25-26). Pranowo mengatakan, Jawa Tengah sangat dipengaruhi oleh Islam tradisional yang ditemukan dalam kehidupan pesantren, agama dan sosial-budaya penduduk desa dan juga hubungan antara desa-desa pada umumnya yang berpusat pada masjid berjalan dengan baik. Bahkan, baik pesantren maupun pesantren tetap sebagai pilar utama Islam tradisional. Islam masih merupakan ukuran kebebasan untuk mengekspresikan agama, baik di desa dan bahkan meluas ke kota Jawa Tengah (2010: 159-310). Pohl meneliti pendidikan Islam di Jawa Tengah mengatakan, fenomena pendidikan Islam di pesantren, sekolahsekolah Islam swasta, dan juga sekolahsekolah Islam umum sebagai tren adanya perkembangan pendidikan Islam di Indonesia yang mampu menginspirasi dunia (2009: xvii, 84-143).

Anehnya, benih-benih konservatisme dan radikalisme di Jawa Tengah oleh hasil penelitian Hasan komposisi sosial dari mereka yang terlibat didalamnya justru sebagian berasal dari sejumlah daerah Jawa Tengah, yaitu Solo, Wonosobo, Temanggung, Semarang, Kebumen, Purwokerto, dan Cilacap. Di daerah-daerah ini, pemuda Muslim membentuk semacam konservatisme dan radikalisme (2006: 159-160). Data itu bagaimanapun menjadi indikator radikalisasi Islam berhasil tumbuh. Belum lagi selama Mei 2019, ada penangkapan 8 tersangka teroris Kudus, Grobogan, Sragen, dan Magelang, Jawa Tengah. Berita terbaru dari Jawa Tengah menghadirkan tujuh kepala sekolah menengah, SLB kejuruan 
dan publik di Jawa Tengah yang diindikasikan merangkul radikalisme dan telah dipecat oleh Gubernur, Ganjar Pranowo, tetapi sekarang menerima bimbingan dan pemahaman tentang Pancasila. Saat menghadiri acara Halaqoh Kyai Santri tentang Pencegahan Terorisme di Grand Syahid Hotel Salatiga, Sabtu 14 September 2019, Ganjar mengungkapkan bahwa sekolah itu memang menjadi salah satu tempat yang perlu ditangani segera terkait dengan ideologi bangsa dan negara. Disebutkan Ganjar, bahwa sejumlah guru ini membiakkan radikalisme melalui mata pelajaran dan ekstrakurikuler.

Agar lebih konkret, saya akan menampilkan keadaan kota Salatiga. Persepsi publik, Salatiga ialah 1 dari 10 kota paling toleran di Indonesia. Salatiga ialah 1 dari 35 Kabupaten dan kota Jawa Tengah yang bebas merayakan festival keagamaan di pusat kota. Kristen bebas merayakan Natal dan Paskah di alun-alun Salatiga tiap tahun. Festival agama juga bebas bagi Islam Salatiga. Masyarakat Tionghoa juga bebas merayakan budaya dan agama di seluruh kota, di mana sebelum 2011 ini tidak mungkin. Kenyataan di permukaan kota Salatiga, tahun 2010-2012, Seo melihatnya sebagai keberhasilan manajemen agama oleh negara di Indonesia (2013: 107). Kenyataannya, Detasemen 88 menangkap Avik Rizal Fattah, seorang pemuda berusia 25 tahun di kota Salatiga, warga Imam Bonjol, Sidorejo, Rabu, 3 Oktober 2018. Ia diduga terlibat dalam jaringan cyber terorism. Jumat, 27 September 2019, Wawan Wicaksono, seorang tersangka teroris berusia 40 tahun ditangkap Densus 88 di Argo Tunggal Ledok, Argomulyo, Salatiga.

Di tengah situasi urbanisasi Jawa Tengah, di Salatiga terjadi kompetisi pendidikan yang makin meruncing. Masyarakat terdistribusi berdasarkan identitas agama yang dipilih oleh orang tua. Islam modern mengirim anak-anak ke Muhammadiyah. Islam tradisional mengirim anak-anak ke Nahdlatul Ulama berbasis pesantren. Yang lebih mampu memilih sekolah Al-Azhar. Protestan memilih sekolah Kristen oleh sinode gereja. Tionghoa nyaman bersekolah di Sekolah Bethany atau di Sekolah Laboratorium UKSW. Katolik sekolah di Pangudi Luhur. Komunitas urban internasional Salatiga ngumpul di Mountain View International School. Realita paradoks Jawa Tengah tersebut membutuhkan terobosan baru dari sektor pendidikan.

Saya melihat kebutuhan kaum kota berpendidikan ialah justru harus memperkuat kecintaan lokalitas dan identitas Salatiga dan nasionalisme namun tak tertinggal dari budaya maupun pergaulan dunia. Untuk itu, saya menciptakan JS sebagai contoh pendidikan yang didirikan dan dikelola seorang Kristen untuk memenuhi hasrat kaum kota untuk berpendidikan bergaya dengan mutu istimewa. Saya, pendiri JS, secara naratif akan memberikan satu contoh empirik model pendidikan yang bisa berkompetisi di tengah pertarungan pendidikan perkotaan di Indonesia. Sejak Agustus 2012 hingga sekarang, JS adalah sekolah nasional (dengan Kelompok Bermain, PAUD, TK, SD. JS telah menjadi tempat bersekolah untuk anak-anak dari 17 negara bermain bebas di alam, tepat di tengah situasi paradoks pendidikan Jawa Tengah. Saya akan menjelaskan JS dilihat sebagai arena pendidikan yang "klik" dengan kebutuhan masyarakat kota di mana setiap orang berbeda dalam agama, bangsa dan negara, dapat belajar dan hidup bersama. 
Hadirnya JS sebelumnya telah melewati penelitian berkesinambungan akan kebutuhan pendidikan masyarakat kota berpendidikan. Saya pernah kuliah di kota ini sejak tahun 1997-2002 di Sekolah Tinggi Teologi Salatiga (STTS) sebelumnya. Saya pindah ke Yogyakarta untuk melanjutkan pendidikan di Universitas Kristen Immanuel Jurusan PAK (2002-2004), Magister Pendidikan Jurusan Non-Formal di Universitas Negeri Yogyakarta (2005-2009), dan Universitas Islam Negeri Sunan Kalijaga Yogyakarta, Jurusan Studi Islam dengan keahlian Islam Politik dan Gerakan Sosial EkonomiPolitik Masyarakat Urban (2009-2018). Sejak 2007, saya menjadi dosen di STTS hingga sekarang. Juli 2012, saya dan keluarga akhirnya kembali ke Salatiga untuk mendirikan JS. Mendirikan JS tentu saja akumulasi pengalaman dan ilmu kependidikan menjadi satu paket yang berguna untuk pengelolaan JS. Pengalaman dan ilmu ditambahkan pula dengan kehadiran istri yang sangat vital karena berpengalaman sebagai tenaga misi Afrika Tengah 1990-2007. Di sana bersama tim, ia menjalankan pendidikan non-formal bagi anak-anak korban Perang Sipil di Sudan. Sebelum mendirikan JS, disertai doa dan ilmu tentu saja, kami bertanya langsung secara santai kepada sejumlah masyarakat di pusat-pusat perbelanjaan baik tradisional maupun supermarket, swalayan ataupun ketika berinteraksi di manapun tentang kerinduan akan sekolah seperti apa yang mereka impikan. Data ini mau mengatakan, JS hadir dalam kebutuhan dan gaya hidup kaum urban dengan perpaduan pengalaman dan ilmu pendidikan.

Dalam perjalanannya, JS menjadi arena sosial untuk kebutuhan masyarakat internasional di Jawa Tengah. Hingga saat ini, ada 121 anak belajar di JS di mana
$38,02 \%$ atau 46 di antaranya adalah warga negara asing. JS adalah sekolah swasta nasional dengan jalur pendidikan non formal dengan konsep sekolah alam di tengah kota mulai dari Kelompok Bermain hingga kelas 4 SD (Juli 2020 akan mulai ada kelas 5 SD). Ada ekstrakurikuler, yakni tarian modern seperti Hip-Hop, Program Olahraga Futsal, keterampilan linguistik Mandarin. JS menerima jenis pendidikan Anak Berkebutuhan Khusus dengan konsep pendidikan inklusif. Anak ("cacat fisik ataupun mental") di setiap tingkat dengan bantuan khusus guru bayangan belajar bersama dengan yang normal.

Paragraf sebelumnya menegaskan perlunya memikirkan ulang Pendidikan Kristen agar tidak terlalu harus ditampilkan oleh "brand bisnis" demi penonjolan identitas seperti kata Stevenson (2007: 152). Di JS yang jauh lebih substansial ialah nilai-nilai yang immersive dalam realitas pembelajaran tiap hari. Saat bersamaan, JS menjadi instrumen penantang ulang, bagaimana memikirkan kembali apa yang sebenarnya ada baiknya, seperti kata Volpe, identitas Kristen yang terlalu bersifat doktrinal dan pemuridan khusus (2012), karena itu hanya bisa diberlakukan secara efektif dan ketat untuk kalangan terbatas yakni Kristen saja, tidak mudah diterapkan ke area yang lebih luas dalam keadaan masyarakat internasional.

JS berkomitmen untuk memberikan cinta, keamanan, dan pendidikan berkualitas lewat pembelajaran dan permainan di lingkungan dengan vegetasi alami. Alam diperlukan manusia kota karena tiap hari terpapar polusi udara. Bangunan JS, ruang kelas, kantor, ruang ekstra kurikuler dibangun terbuka. Tidak ada lantai semen dan batu bata di seluruh area bermain sehingga anak tidak terluka jika jatuh. Bahkan, untuk menambah pohon 
yang tumbuh di lahan yang ada, JS juga sengaja melakukan reboisasi pohon, bunga dan tanaman lain sebagai area bermain sekaligus media pembelajaran. sekolah alam tepat bagi kaum kota yang "stress" dan tergantung dengan layar dan "gadget." Ini mau mengatakan, JS diciptakan dengan mengerti kebutuhan dasar anak dan mengatasi persoalan yang diidap anak kota.

Pendidikan kota yang baik agar dapat mandiri secara finansial. JS didirikan tidak bergantung kepada sponsor baik di Indonesia apalagi di luar negeri. Dana pendidikan diperoleh dari orang tua anak. Seluruh proses belajar mengajar di JS dilakukan dalam bahasa Inggris namun anak bebas menggunakan bahasa ibu sendiri di luar jam belajar. Untuk memperkenalkan, memperkuat nasionalisme, JS menggunakan bahasa Indonesia sebagai bahasa pengantar selama 10-20 menit setiap hari. Tidak ada formalitas seragam sekolah untuk, dan "Tidak Ada Toleransi untuk Penindasan." Anak harus menghormati orang lain dan lingkungan. Meskipun di JS ada anak dari berbagai negara dan bahasa tidak ada persyaratan kemahiran bahasa. Semua orang bisa berkumpul dan hidup bersama. Setiap tingkat pembelajaran menggunakan tematik diciptakan sendiri berkerangka kurikulum nasional. Tapi, "delivery" isi dan proses pembelajaran menyenangkan sesuai dengan keunikan anak. Sampai di sini, menurut saya, seperti kata Cross, Campbell-Evans, Gray, (2018: 23-38), pendidikan Kristen yang baik diciptakan melampaui batas-batas asumsi pengaruhnya berdampak pada kehidupan sosial anak. Kebanggaannya sebagai manusia memiliki kewargaan yang diakui bermartabat di manapun.

JS menjadi sangat menarik dan sangat relevan tidak hanya di kota Salatiga dan Indonesia tetapi juga dunia saat ini karena secara unik memungkinkan orang tua dan menjadi teman dalam mengekspresikan iman dan identitas sendiri. Sekolah ini dibutuhkan di tengahtengah fundamentalisme dan radikalisme agama, terutama karena komunitas kota yang perpecah akibat pemahaman teologis termasuk komersialisasi pendidikan urban. Kehadiran JS tidak ahistoris. Ia membangkitkan memori sejarah, Salatiga seperti kata Colombijn, sebagai kawasan urban internasional (113-144). Di masa lalu, kota ini telah dihuni oleh orang Eropa, Cina, Arab, dan komunitas lokal hidup berdampingan dengan Belanda, Jepang hingga kemerdekaan Indonesia dengan toleransi. Dengan semangat menghidupkan kembali sejarah kota Salatiga lama, JS menyediakan tempat dan suasana belajar yang penuh petualangan. JS merealisasikan isu kampanye politik Salatiga yaitu internasionalisasi sektor pendidikan oleh Walikota dan Wakilnya tahun 2011-2017 hingga 2017-2022. (Tambunan, Oktober 2018). Dari penjelasan ini jelas tampak kemampuan hasil pembelajaran dari lulusan PAK yang beripikir global bertindak lokal selaras dengan persoalanpersoalan dalam urbanisasi.

Anak JS berbeda dalam nilai agama dan budaya yakni Indonesia, Amerika Serikat, Kanada, Australia, Korea Selatan, Jepang, Brasil, Argentina, Kosta Rika, Sri Lanka, India, Jerman, Belanda, Irlandia, Liberia, Ethiopia, dan Turki. Sistem sekolah seperti ini tidak mudah ditemukan di negara Barat ataupun di wilayah lain di Indonesia. Oleh kehadiran anak dari negara berbeda, di JS ada proses immerse budaya internasional. Ini akan memperluas pesanpesan kepada dunia yang melebihi apapun dari apa yang pernah bisa dituliskan di atas kertas. Saya hendak mengatakan, yang 
terjadi dan berproses di JS mengusung "konten" suara realitas lebih kuat dari tertulis. JS menjadi tiang kerekan bendera pembawa kebanggaan Indonesia Kristen bersama guru dan karyawan dalam semangat progresif sekaligus harapan dan doa. Mungkin saja hal itu belum terwujud sekarang. Tetapi, mengingat anak JS dari sejumlah negara, maka dalam tempo 20-30 tahun akan menjadi pemimpin dunia di area masing-masing.

\section{Kesimpulan}

Tulisan ini tegas memperlihatkan belajar bagi orang dewasa tidak lagi mengumpulkan pengetahuan transformatif. Pendidikan harus diubah menjadi arena sosial untuk menghasilkan manusia pembelajar dewasa dengan seperangkat pengalaman dan alat cipta sesuatu agar bermanfaat serbaguna. Jungle School sebagai contoh kemampuan lulusan pendidikan tinggi Kristen menterjemahkan hasil belajar orang dewasa berciri progresif untuk menciptakan sekolah bagi kaum kota yang kepayahan menghadapi paradoks pembangunan kota di Indonesia demi mengejar modernisasi dan tekanan urbanisasi. JS bisa menginspirasi pendidikan daerah tertinggal dalam kesulitan akan fasilitas tetapi selalu mimpi ingin sama dengan glamoritas pendidikan kota, meskipun perlu dibahas lanjut karena belum dipaparkan di sini.

\section{Daftar Pustaka}

Aritonang, Jan S. Sikap dan strategi lembaga-lembaga pendidikan kristen menghadapi era revolusi industri 4.0 (97106). Prosiding seminar nasional dan call for papers. Membangun indonesia di era revolusi industri 4.0 (pp. 107-121). Program Pascasarjana Universitas Kristen
Indonesia, Jakarta, Rabu, 7 November 2018.

Boggs, Davil L. Philosophies at issues. Dalam Burton W. Kreitlow and Associates (eds.), Examining controversies in adult education (pp. 1-10). San Francisco: Jossey-Bass Publishers, 1989.

Bruner, Jerome. The process of education (pp. 43). Cambridge, Massachusetts: Harvard University Press, 1960.

Calleja, Colin. “Jack mezirow's conceptualisation of adult transformative learning: A review." Journal of Adult and Continuing Education, 20, 1 (2014): 117136.

Chen, Joseph C. "Nontraditional adult learners: The neglected diversity in postsecondary education." SAGE Open Special Issue (2017): 1-12.

Carlsen, A., C. Holmberg, C. Neghina, A. Owusu-Boampong. Closing the gap: Opportunities for distance education to benefit adult learners in higher education (pp. 16). Hamburg, Germany: UNESCO Institute for Lifelong Learning (UIL), 2016.

Colombijn, Freek. Sing of the times: Symbolic change arround indonesian independence. Dalam Peter J.M. Nas, Annemarie Samuels (eds.), Hyper city (pp. 113-144). London: Kegan Paul, 2006.

Cranton, Patricia. Understanding \& promoting transformative learning: A guide to theory and practice. Sterling, VA: Stylus Publishing, 2016.

Cranton, Patriacia., E.W. Taylor, "Transformative learning theory: Seeking a 
more unified theory." Dalam Patricia Cranton, E.W. Taylor \& Associates (eds.). Handbook of trans formative learning: Theory, research, and practice. San Francisco, CA: Jossey-Bass, 2012.

Cranton, Patricia. "Transformative learning." Dalam P. Mayo (ed.), Learning with adults: A reader (267-274). Rotterdam, Netherlands: Sense Publications, 2013.

Cross, Graeme, Glenda Campbell-Evans, Jan Gray. "Beyond the assumptions: Religious schools and their influence on students' social and civic development." International Journal of Christianity and Education, 22, 1 (2018): 23-38.

Dockery, David S. "Change, challenge, and confession: Looking toward the future of christian higher education." Christian Education Journal, 16, 2 (2019): 296-308.

Drago-Severson, Eleanor. Leading adult learning: Supporting adult development in our schools. California: SAGE Publications, Inc., 2009.

Ellison, Marvin M., Kelly Brown Douglas. Sexuality and the sacred: Sources for theological reflection (pp. 254). Louisville, Kentucky: Westminster John Knox Press, 2010.

Finger, Matthias, Jose Manuel Asun, Adult education at the crossroads: Learning our way out (pp. 1-2). London: Zed Books, Ltd, 2001.

Hammond, Michael D. "Christian higher education in the united states: The crisis of evangelical identity." Christian Higher Education, 18, 1-2 (2019): 3-15.
Hasan, Noorhaidi. Laskar jihad: Islam, militancy, and the quest for identity in postnew Order (pp. 159-160). Itacha, New York: SEAP Cornel University, 2006.

Hermans, Chris A. M., Mary Elizabeth Moore. Hermeneutics and empirical research in practical theology: The contribution of empirical theology by johannes a. van der ven (pp. 49). Leiden: Koninklijke Brill NV, 2004.

Husen, Torsten. "Talent, opportunity and career: A twenty-six year follow-up." The School Review (Chicago). 76, (1968): 190209.

Husen, Torsten. "Life-long education in the educative society. International Review of Applied Psychology, 17 (1968): 87-99.

Kim, Eugene C., Richard D. Kellough. Resource guide for secondary school teaching: Planning for competence (pp. vii). New York: Macillan Publishing Co., Inc., 1983.

Illeris, Knud. An overview on transformative learning: Contemporary theories of learning (pp. 90-105). London and New York: Routledge, 2009.

Jasin, Anwar. "Indonesia in the modern world." Journal of Christian Education, 6, 2 (1963): 93-100.

Knowles, Malcom. The adult learner: The definitive classic in adult education and human resources development. Houston, TX: Gulf Publishing, 1998.

Lengrand, Paul. An introduction to lifelong education (pp. 73). Paris: Unesco, 1970. 
Lickona, Thomas. Educating for character: How our schools can teach respect and responsibility (pp. 7). New York: Bantam Books, 1992.

Lickona, Thomas. Character matters: How to help our children develop good judgment, integrity, and other essential virtues (pp. 277). New York: Simon and Schuster, 2004.

Lickona, Thomas. Moral development and behavior: Theory, research, and social issues (pp. 400). Austin Texas: Holt, Rinehart and Winston, 1976.

Marique, Pierre Joseph. The philosophy of christian education (pp. 74). New Jersey: Prentice-Hall, Incorporated, 1939.

Marsick, V., J. Mezirow. "New work on transformative learning." Teachers College Record, 25 January 2012.

Merriam, Sharan B., Laura L. Bierema. Adult learning: Linking theory and practice. New York: John Wiley \& Sons Inc, 2013.

Mezirow, Jack. Education for perspective transformation: Women's re-entry programs in community colleges. NewYork: Teachers College Columbia University, 1978.

Mezirow, Jack. "Perspective transformation." Adult Education, 28 (1978): 100-110.

Mezirow, Jack. "A critical theory of adult learning and education," Adult Education Quarterly, 32, 3 (1981): 3-24.
Mezirow, Jack. A critical theory of selfdirected learning. Dalam S. Brookfield (ed.). Self directed learning: From theory to practice (pp. 25). San Francisco, CA: Jossey-Bass, 1985.

Mezirow, Jack. "Transformation theory and social action: A response to collard and law." Adult Education Quarterly, 39, 3 (1989): 169-175.

Mezirow, Jack. Fostering critical reflection in adulthood. San Francisco, CA: JosseyBass, 1990.

Mezirow, Jack. Transformative dimensions of adult learning (pp. 4). San Francisco, CA: Jossey-Bass, 1991.

Mezirow, Jack. "Beyond freire and habermas: Confusion a response to bruce pietrykowski." Adult Education Quarterly, 46, 4 (1996): 237-239.

Mezirow, Jack, \& Associates. Learning as transformation: Critical perspectives on a theory in progress. San Francisco, CA: Jossey-Boss, 2000.

Mezirow, Jack. Transformative learning in practice: Insights from community, workplace, and Higher Education (pp. 168169). New Jersey: John Wiley \& Sons Inc, 2009.

Mezirow, Jack. "Laearning to think like an adult: Core concepts of transformation theory." Dalam E.W. Taylor, P. Cranton \& Associates (eds.). The handbook of transformative learning: Theory, research, and practice (73-95). San Francisco. CA: Jossey-Bass, 2012. 
Moser, Paul K., Arnold Vander Nat. Human knowledge: Classical and contemporary approaches (pp. 66). Oxford, UK: Oxford University Press, 1987.

Newton, Issach. Preface and general scholium newton. Berkeley: University of California Press, 1934.

Parkyn, George W. Towards a conceptual model of life-long education (pp. 7). Paris: Unesco, 1973.

Pohl, Florian. Islamic education and the public sphere: Today's pesantren in indonesia (pp. xvii, 84-143). Munster and New York: Waxmann, 2009.

Pranowo, M. Bambang. Memahami islam jawa (pp. 159-310). Jakarta: Pustaka Alvabeta Kerjasa dengan Indonesian Institute for Society Empowerment, 2010.

Ricklefs, Merle Calvin. A history of modern indonesia since C.1200 fourth edition (pp. 202). New York: Palgrave Macmillan, 2008.

Ricklefs, Merle Calvin. Islamisation and its opponents in java: A political, social, cultural and religious history, c. 1930 to the present (pp. 21-22, 98). Hawaii: University of Hawaii Press, 2012.

Segall, William Edwin. School reform in a global society (pp. 181). Lanham, Maryland: Rowman \& Littlefiel Publishers, Inc., 2006.

Seo, Myengkyo. State management of religion in indonesia (pp. 107). London and New York: Routledge, 2013.
Shires, Henry H., Randolp C. Miller. Christianity and contemporary scene (pp. 196-201). New York: Morehouse-Gorham, 1943.

Stevenson, Tyler Wigg. Brand jesus: Christianity in a consumerist age. New York: Seabury Books, 2007.

Subhan, Arief. Lembaga pendidikan islam di indonesia abad ke-20: Pergumulan antara modernisasi dan identitas (pp. 3). Jakarta: Kencana, 2012.

Shukla, PD. Life long education: Scholar select. Kittery, ME: Franklin Classics Trade Press, 2018.

Tambunan, Elia. Kristenologi: Ilmu pengembangan masyarakat kristen (pp. 6372). Yogyakarta: Illumination Publishing, 2012.

Tambunan, Elia. Teologi sebagai sains (pp. 3-11). Yogyakarta: IllumiNation Publishing, 2012.

Tambunan, Elia. Gerakan intelektual: Postmodernisasi ilmu pengetahuan mengobati penyakit pendidikan tinggi keagamaan kristen, Gema FIRMAN, 1, 1 (2012): 96138.

Tambunan, Elia. Islamisme, kapitalisasi ruang kota, dan gerakan politik masyarakat urban: Aliansi ekonomi-politik pks, kristen, dan tionghoa di salatiga. Disertasi. Universitas Islam Negeri Sunan Kalijaga Yogyakarta, Oktober 2018.

Tambunan, Elia. Pendidikan kristen di masyarakat urban. Prosiding seminar nasional dan call for papers. Membangun indonesia di era revolusi industri 4.0 (pp. 
107-121). Program Pascasarjana Universitas Kristen Indonesia, Jakarta, Rabu, 7 November 2018.

Taylor, Edward W., Patricia Cranton. The handbook of transformative learning: Theory, research, and practice. San Francisco, CA: Jossey-Bass, 2012.

Taylor, E. W. "Building upon the theoretical debate: A critical review of the empirical studies of mezirow's transformative learning theory." Adult Education Quarterly, 48, 1 (1997): 34-59.

Vink, Amanda. Education for all. New York: Rosen Publishing Group Inc., 2020.

Volpe, Medi Ann. Rethinking christian identity: Doctrine and discipleship. New Jersey: Wiley-Blackwell, 2012.

Wildemeersch, Danny., Matthias Finger, Theo Janses (eds.). Adult education and social responsibility: Reconciling the irreconcilable? (pp. ix). New York: Peter Lang Publishing, Inc, 2001.

Williams, Sue. "Corporate Social Responsibility Partnerships." UNESCO, 119 (2000): 4-5.

Zahnd, Markus. Model baru perancangan kota yang kontekstual: Kajian tentang kawasan tradisional di kota semarang dan yogyakarta suatu potensi perancangan kota yang efektif (pp. 25-26). Yogyakarta: Penerbit Kanisius Bekerjasama dengan Soegijapranata University Press, 2008. 